JOURNAL Of CONTEMPORARY INDONESIAN ART

Jurusan Seni Murni

FSR ISI Yogyakarta

ISSN: 2442-3394

E-ISSN: 2442-3637

\section{PARADOKS BUNUH DIRI SEBAGAI IDE DALAM PENCIPTAAN KARYA SENI GRAFIS}

\author{
Oleh: Aminuddin M. Abdullah
}

Institusi: Institut Seni Indonesia Yogyakarta

\begin{abstract}
ABSTRAK
Rasa empati terhadap peristiwa kemanusiaan menjadi latar belakang ide penciptaan karya seni grafis. Kemudian ketakutan-ketakutan penulis terhadap kematian yang seolah-olah segera menjumpai setiap harinya. Banyak pihak yang mendapat keuntungan dari peristiwa tersebut tetapi mereka tidak merasa jika mereka sedang diuntungkan. Jika di suatu tempat terjadi peristiwa bunuh diri, maka bisa dipastikan akan banyak orang atau masyarakat yang menyaksikan. Terlebih lagi media, pastilah media tersebut akan memberitakan dengan sangat intens. Media akan memberitakan tragedi tersebut dengan gestur yang sepertinya sedih dan seakan berempati. Padahal jika diteliti lebih dalam, para awak media tersebut justru mendapatkan pundi-pundi uang dari hasil pemberitaan tragedi tersebut. Bentuk yang naturalistik dan figuratif serta simbol-simbol yang menggambarkan paradoks di setiap tragedi yang terjadi. Serta pegunungan, pepohonan yang menjadi setting pemandangan pada setiap karya menggambarkan suasana pedesaan yang masih asri.
\end{abstract}

Kata kunci: Cukil kayu, Metode seni grafis, Paradoks bunuh diri

\begin{abstract}
A sense of empathy for humanitarian events is the background for the idea of creating graphic art works. Then the writer's fears of death seem to come across every day. Many parties benefited from the incident but they did not feel that they were being benefited. If a suicide occurs, it is certain that many people or the public will witness it. What's more, the media, surely the media will report very intensely. The media will report on the tragedy with a gesture that seems sad and empathetic. In fact, if investigated more deeply, the media crew actually got coffers of money from the news of the tragedy. There are naturalistic and figurative forms and symbols depicting paradoxes in every tragedy that occurs, as well as mountains and trees that become the setting for the scenery in each work depicting a beautiful rural atmosphere.
\end{abstract}

Keyword: Printmaking method, Suicide paradox, Woodcut 


\section{A. Pendahuluan}

Berawal dari ketertarikan penulis terhadap tingkah laku manusia, khususnya manusia Indonesia yang selalu membuat gelak tawa, tangis, hingga manusia lain yang memperhatikannya terperangah. Menurut Mochtar Lubis dalam bukunya, salah satu ciri manusia Indonesia yang cukup menonjol adalah hipokrit alias munafik. Berpura-pura, lain di muka lain di belakang. Merupakan sebuah ciri utama manusia Indonesia sudah sejak lama, sejak mereka dipaksa oleh kekuatan-kekuatan dari luar untuk menyembunyikan apa yang sebenarnya dirasakan atau dipikirkannya ataupun yang sebenarnya dikehendakinya. Karena takut akan mendapatkan ganjaran yang membawa bencana bagi dirinya, manusia Indonesia masa kini adalah segan dan enggan bertanggung jawab atas perbuatannya, keputusannya, kelakuannya, pikirannya, dan sebagainya. Frasa "bukan saya" adalah kalimat yang cukup populer pula di mulut manusia Indonesia (Lubis, 2013, p. 18).

Pada setiap permasalahan, manusia Indonesia cenderung main aman, tidak peduli, bahkan mengambil keuntungan sebanyak mungkin dari setiap permasalahan yang terjadi. Sehingga jika individu manusia melakukan kesalahan, maka masyarakat akan menghakiminya. Tanpa peduli akan nasib yang akan diderita oleh individu tersebut. Bahkan jika individu yang tersakiti oleh penghakiman itu memilih untuk melakukan bunuh diri, penghakiman itu akan semakin menjadi-jadi dan keuntungan yang didapat akan semakin berlimpah. Ketika mereka ditanya apakah mengambil keuntungan dari tragedi tersebut? Maka jawabannya, "Kami hanya berempati saja." Jika pertanyaannya, "Apakah anda tidak kasihan?" Jawabannya, "Kami tidak mengenalnya, mengapa kami harus kasihan, dan yang menghujat bukan kami saja".

Rasa empati terhadap peristiwa kemanusiaan menjadi latar belakang ide penciptaan karya seni grafis. Kemudian ketakutan-ketakutan penulis terhadap kematian yang seolah-olah segera menjumpai setiap harinya juga menjadi latar belakang ketertarikan pada tema ini. Anak-anak dan orang-orang yang berusia muda, mempunyai pikiran bahwa mereka akan hidup selamanya, sebaliknya manusia yang berusia lanjut atau sudah tua, merasa kematian senantiasa akan menjumpainya setiap detik.

Kehidupan masa kecil penulis yang hidup di sebuah pedesaan juga banyak mempengaruhi proses penciptaan karyakarya ini. Pemandangan alam yang masih asri, mulai dari pepohonan, sungai, hingga masyarakatnya yang bahagia, ramah dan bersahaja adalah kelaziman yang dialami penulis. Suatu ketika penulis menemukan sebuah keanehan yang terjadi di balik suasana yang damai dan tenang itu. Seperti tragedi pembunuhan, bunuh diri, bahkan kejadian di mana pencuri atau begal yang diamuk oleh masyarakat hingga tewas. Hal-hal itu yang kemudian membuat penulis berpikir bahwa di sebuah tempat yang damai dan tenang pun masih ada tragedi berdarah dan sadis.

Sebagian besar manusia menganggap bunuh diri atau mati yang tidak sewajarnya dianggap salah dan mengerikan, begitupun dengan penulis. Tetapi, pandangan berbeda justru muncul dari orang-orang yang dianggap introvert atau anti sosial, serta kaum-kaum yang termarjinalkan; dan mendengar cerita atau kisah-kisah mereka, dari bincang-bincang dengan teman yang merasakan, penulis tidak langsung mengambil kesimpulan bahwasanya mereka salah, mereka dosa, mereka bertindak bodoh, bahkan memutuskan pasti mereka akan masuk ke neraka seperti yang dikemukakan oleh sebagian besar manusia pada umumnya. Banyak penyebab terjadinya bunuh diri, salah satunya tekanan psikologis yang diderita oleh seorang individu yang disebabkan karena pengaruh buruk pemberitaan media massa atau media sosial. Media tersebut tidak lagi mempedulikan persyaratan pemberitaan yang baik dan benar sesuai aturan. Salah satu tragedi yang menarik perhatian penulis adalah saat ia membaca artikel tentang pemberitaan tentang seorang anak yang dituduh pelacur. Saat ini media mengekspos beritanya tan- 
pa mengoreksi beritanya terlebih dahulu dan mendapatkan keuntungan dari kabar tersebut. Peristiwa itu yang menjadi latar belakang penciptaan karya seni grafis ini.

\section{B. Rumusan Penciptaan}

Dari gagasan yang disampaikan di atas dapat dirumuskan beberapa pernyataan sebagai berikut: 1. Bagaimana paradoks dalam peristiwa bunuh diri menjadi ide penciptaan? 2. Bagaimanakah visualisasi paradoks bunuh diri dalam karya seni grafis?

\section{Teori dan Metode \\ 1. Teori}

Paradoks: Paradoks mengandung dua kebenaran yang bertentangan. Kebenaran suatu paradoks terletak pada kesatuan kedua kebenaran yang bertentangan itu. Paradoks berhubungan dengan kekhasan kedudukan manusia di dunia ini. Manusia termasuk dalam dunia alam, namun sekaligus transenden terhadapnya. Manusia bebas dan terikat, otonom dan tergantung, terbebas dan terbelenggu, sosial dan personal, duniawi dan ilahi, rohaniyah dan jasmaniyah, fana dan baka (Snijders, 2004, p. 77). Sedangkan menurut Suharso dan Ana Retnoningsih paradoks adalah pernyataan yang seolah olah bertentangan dengan pendapat umum atau kebenaran, tetapi kenyataanya mengandung kebenaran (Suharso \& Retnoningsih, 2009, p. 359).

Bunuh Diri: Bunuh diri (suicide) dapat didefinisikan sebagai upaya seseorang untuk membunuh dirinya sendiri dengan sengaja. Kata suicide berasal dari kata latin sui yang berarti diri (self), dan kata ceadere yang berarti membunuh (to kill) (Al-Husain, 2005, p. 6).

Pada teori perwujudan terdapat bentuk-bentuk yang ada dalam imajinasi penulis yang bersifat naturalistik dan figuratif. Aliran Naturalis sendiri adalah usaha menampilkan objek realistis dengan menekankan seting alam, tetapi tidak mempunyai objek tertentu dan merupakan hasil susunan/komposisi dari unsur-insur alam yang indah-indah menurut senimannya; lalu hasil karyanya jelas bersifat jauh dari kenyataan, bahkan bersifat idealistik imajinatif dan konstruktif. Kaum natularis berusaha mengungkapkan segala sesuatu sesuai dengan wujud kenyataan (nature) manusia atau alam dengan fenomenanya yang kemudian diungkapkan sebagaimana mata kita memandang dan menangkap. Figur imajinatif disajikan dan dipadukan dengan warna dan bentuk berupa figur manusia, hewan, tumbuhan dan benda-benda yang ada di sekitar kita sesuai dengan imajinasi penulis.

Berdasarkan teori dan praktik yang didapat selama belajar di bidang seni rupa murni khususnya seni grafis, penulis ingin menyampaikan gagasan melalui karya seni grafis dengan teknik cukil kayu.

Penulis memiliki keresahan terhadap banyaknya masyarakat yang menghakimi dan menghujat mereka yang dianggap salah, serta adanya oknum masyarakat tertentu yang merasa senang akan hal tersebut. Keresahan lain ada pada kasus bunuh diri dengan permasalahan yang kompleks, beserta profesi tertentu yang memanfaatkan tragedi bunuh diri itu. Keresahan-keresahan tadi ingin dituangkan lewat teknik cetak tinggi dengan menggunakan media papan Mdf dan teknik pewarnaan reduksi. Mdf sendiri adalah (Medium density fibrebord) papan material yang tersusun dari kombinasi serat kayu dan serbuk kayu yang dipadatkan dalam tekanan dan temperatur suhu yang tinggi dengan bantuan resin dalam prosesnya. Sedangkan cetak dengan teknik reduksi sendiri yaitu melalui proses pewarnaan secara bertahap dari warna satu kemudian warna berikutnya.

Simbol adalah apa saja yang diberikan arti dengan persetujuan umum dan kesepakatan atau kebiasaan, kata, data, isyarat yang digunakan untuk mewakili sesuatu yang lain: arti, kualitas, abstraksi gagasan, atau objek. Simbol juga merupakan tanda berdasarkan konvensi, peraturan, atau perjanjian yang disepakati bersama. Simbol baru dipahami jika seorang sudah mengerti arti yang telah disepakati sebelumnya (Tinarbuko, 2008, p. 17).

Beberapa karya, menggunakan simbol-simbol yang bersifat objektif seperti 
roda bekas yang digantung, yang mengartikan bahwa sesuatu yang sudah bekas masih bisa digunakan, meskipun tidak pada tempat yang semestinya. Garis pada langit-langit yang mempunyai arti seperti sangkar burung, di mana burung yang terkurung di sangkar tidak bisa bebas dan terbang kemanapun, walaupun jika burung itu dilepasliarkan belum tentu burung itu bisa bertahan hidup. Hal ini dijadikan simbol seperti masyarakat yang hidup di pelosok pedesaan, di mana mereka tidak bisa ke mana-mana karena keterbatasan finansial dan letak geografisnya. Jika mereka bisa keluar dari desa, belum tentu bisa hidup sedamai di desanya.

Selain simbol-simbol di atas penulis juga menggambarkan simbol figur manusia yang menunjukkan suasana interaktif di pedesaan dan figur gadis, sebuah keluarga kecil, serta serangga yang menjadi inti dari cerita. Penggambaran sosok gadis yang sedang menyendiri dan termenung, di hujat oleh masyarakat sekitarnya bahkan ayahnya sendiri, hingga detik-detik saat dia melakukan gantung diri. Seorang pemuda yang sedang sekarat bersimbah darah akibat mobil yang ia kendarai menabrak sebuah pohon di tepi jalan, sekilas seperti kecelakaan, padahal yang terjadi ia sengaja menabrakkan dirinya ke pohon tersebut.

Visualisasi beberapa tempat terjadinya tragedi itu dengan maksud kejadian serupa mungkin dan bahkan sedang terjadi saat ini di tempat lain di belahan dunia lain. Simbol tali menggambarkan tragedi bunuh diri serta tali merupakan simbol untuk mengikat, yang dimaknai mengikat semua kejadian di dunia. Semua kejadian yang terjadi di dunia ini pasti saling berhubungan. Pohon yang selalu ada pada setiap karya mempunyai maksud penghormatan terhadap makhluk hidup yang lebih tua dari manusia. Pohon diyakini jauh lebih dahulu diciptakan oleh Tuhan dari pada manusia.

\section{Metode}

Pada metode perwujudan karya, teknik yang digunakan adalah cukil kayu yang masuk dalam teknik cetak tinggi. Karya yang dihasilkan dibuat berwarna dengan teknik reduksi. Reduksi adalah teknik cukil satu plat Mdf, proses pencukilannya bertahap, dari awal sampai akhir dengan pewarnaan yang bertumpuk dari warna pertama sampai warna terakhir.

Pada perwujudan karya yang bertemakan paradoks bunuh diri, digunakan beberapa elemen-elemen dasar seni rupa, seperti penggunaan warna, bentuk, garis, serta elemen pendukung yang disengaja maupun yang tidak disengaja yang membuat karya bernilai artistik. Perwujudan hasil dari kombinasi bentuk dengan imajinasi dan figur nyata.

Proses berkarya merupakan medium seorang seniman mengekspresikan dirinya menciptakan sebuah karya seni. Pada tahapan berkarya seniman menyelam jauh ke dalam dirinya untuk menuangkan apa yang ada di dirinya. Apa yang menjadikan keresahan dan kesenangan dapat menjadi sebuah ide dalam menciptakan sebuah karya. Rasa ketertarikan berlebih yang membuat seniman seakan-akan terfokus dalam suatu permasalahan dan akhirnya dapat tercipta sebuah karya yang memiliki arti mendalam. Proses penciptaan yang mendalam saat menarasikan sebuah permasalahan hidup, membuat rasa empati seniman ketika membuat sebuah karya mempunyai nilai estetik tersendiri.

Seorang perupa tidak hanya berkarya dan memamerkan sebuah karya, namun juga harus dapat mempresentasikan ide dan gagasan dalam berkarya. Ide dan gagasan dalam proses pembuatan karya sangat penting, karena sebagai akar terbentuknya seni yang diciptakan. Proses berkarya dan pendalaman materi yang diangkat di sebuah karya menjadikan keuntungan karena proses berkarya sama halnya dengan proses belajar merasakan hal yang lebih.

Sebuah karya tidak hanya berisi tentang bentuk dengan elemen rupa seperti garis, warna, teknik, dan bentuk visualnya saja. Namun juga mengenai makna dalam karya menyampaikan sebuah permasalahan hidup yang dirasakan seorang seniman dan diungkapkan lewat sebuah karya. Pada bab ini keseluruhan karya diulas tuntas dari makna dalam karya, gagasan 
dan pesan-pesan yang ingin disampaikan.

Bentuk-bentuk figuratif dengan perpaduan pemandangan alam dan dengan bentuk imajinatif dimunculkan dan dipadukan menjadi satu kesatuan yang utuh. Terdapat simbol-simbol tertentu untuk membuat karakter dan narasi cerita untuk memperkuat cerita visual. Pada Penggunaan beberapa simbol tertentu karya terkesan lebih menarik secara visual.

\section{Hasil dan Pembahasan}

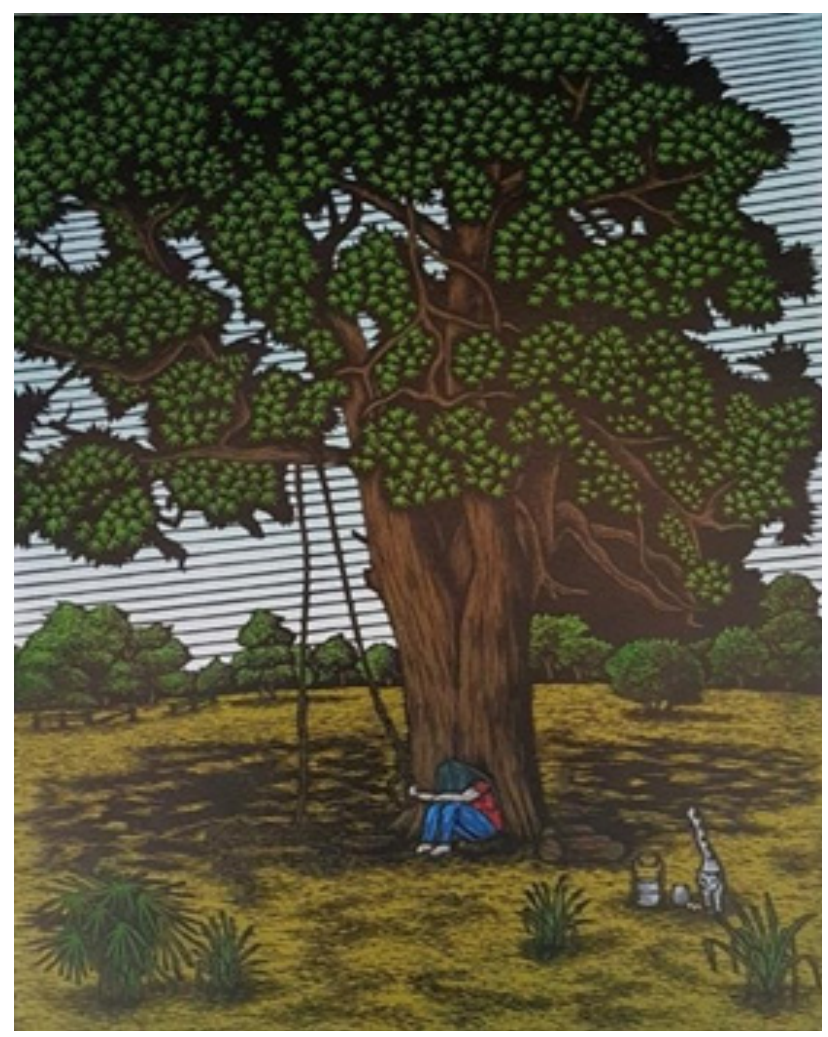

Gb. 1. "Goyah", 2018

Relief Print $41 \mathrm{~cm}$ x $55 \mathrm{~cm}$

(Sumber: Dokumentasi Penulis)

Karya ini bercerita tentang perempuan yang seolah terlihat ingin melakukan bunuh diri. Akan tetapi yang terjadi sebenarnya adalah ia sedang menjalankan garis hidup yang sudah ditakdirkan Tuhan kepadanya. Mungkin sebagian besar manusia menganggap bahwa bunuh diri itu menyalahi takdir Tuhan, karena belum saatnya mati tetapi memaksa untuk mati. Padahal secara logika, mati dengan cara apapun itu memang sudah menjadi garis takdir seseorang atau makhluk hidup itu, sekalipun dengan cara bunuh diri. Karya ini menggambarkan perempuan sedang berada di bawah pohon besar yang rindang memegang seutas tali yang menyimbolkan bunuh diri. lalu ada rantang atau wadah makanan yang menyimbolkan bekal untuknya di kehidupan yang baru. Serta seekor kucing yang menyimbolkan kesetiaan. Kucing adalah salah satu hewan yang setia pada pemiliknya, yang mana manusia terkadang tidak demikian, seekor kucing yang setia mendampingi pemiliknya sampai akhir hidupnya. Karena penulis menganggap orang akan terlihat kesetiaan dan kepeduliannya kepada seseorang jika seseorang itu telah tiada atau meninggal dunia.

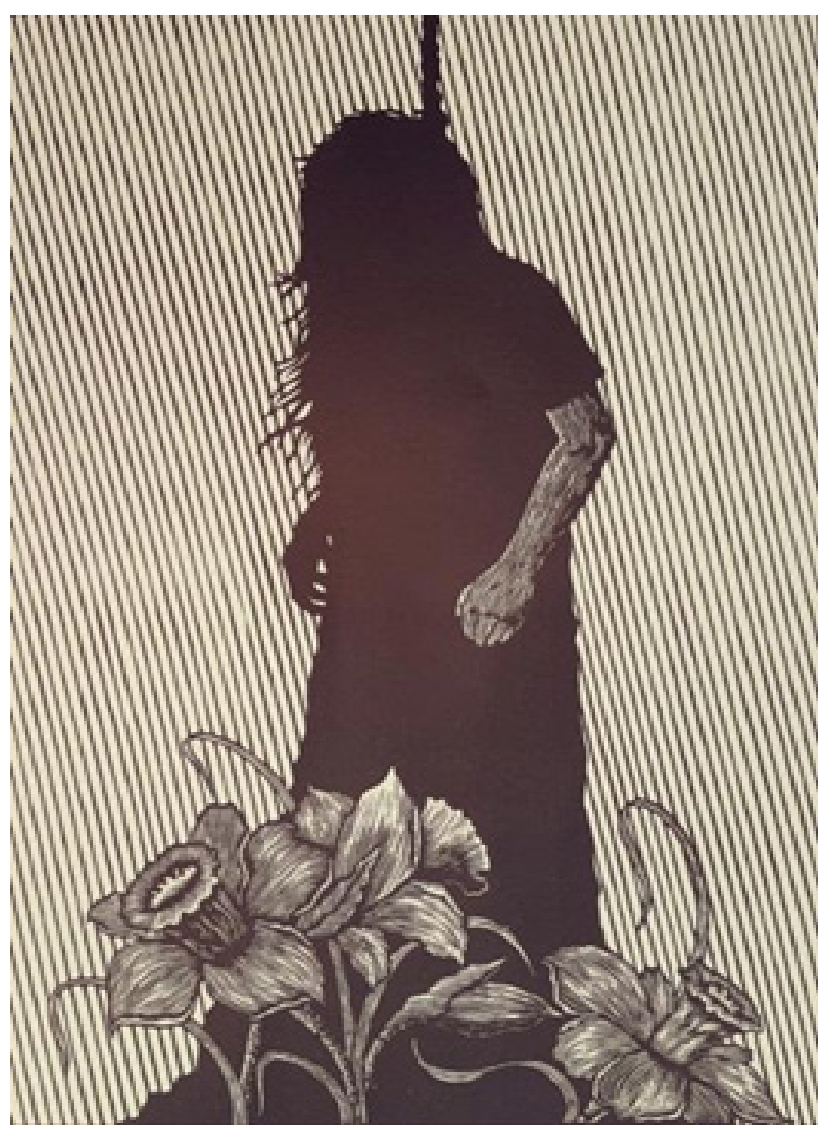

Gb. 2. "Awal yang baru”, 2018

Relief Print $42 \mathrm{~cm}$ x $61 \mathrm{~cm}$

(Sumber: Dokumentasi penulis)

Karya ini bercerita tentang awal yang baru bagi seorang yang melakukan bunuh diri. Jika ada seseorangyang meninggal den- 
gan cara bunuh diri, maka sebagian besar manusia akan menggangap hal itu adalah kesalahan, tindakan bodoh dan dosa yang sangat besar, bahkan kelak arwah mereka tidak diterima oleh Tuhan. Anggaplah semua yang disebutkan itu benar, tapi bukannya semua yang terjadi di dunia ini atas kehendak Tuhan juga? Berarti semua manusia yang mati dengan cara bunuh diri juga dikehendaki oleh Tuhan, jika tidak maka hal itu tidak akan mungkin terjadi.

Pada karya ini menggambarkan sosok siluet perempuan yang sedang gantung diri dengan tali, kemudian di depannya ada beberapa bunga. Bunga tersebut adalah bunga Dafodil yang mempunyai arti awal yang baru. Penulis meyakini bahwa kematian manusia adalah awal dari kehidupan yang baru. Garis diagonal yang menyimbolkan hubungan manusia yang mati dengan cara bunuh diri dengan Tuhannya tidak bisa vertikal atau langsung lurus ke atas, dengan kata lain hubungannya masih mengambang karena dianggap arwahnya tidak diterima disisi Tuhannya.

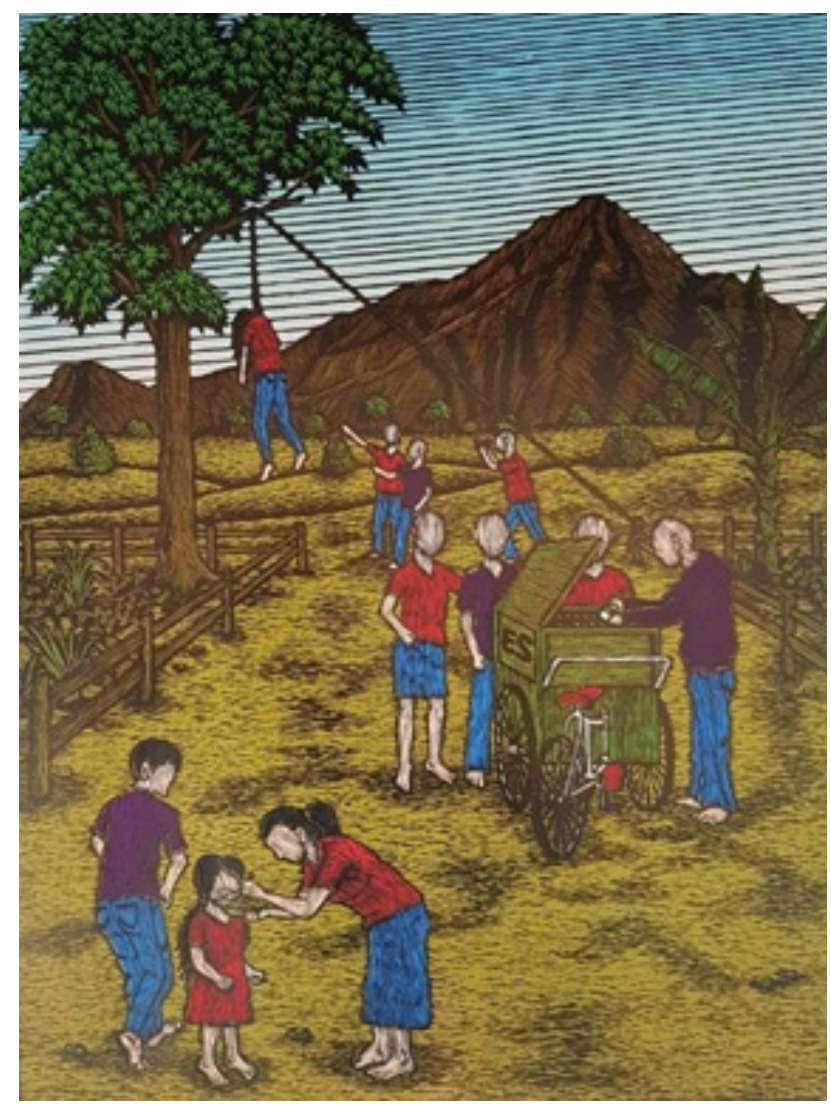

Gb.3. "Kepedulian Mereka”,2018

Relief Print $42 \mathrm{~cm}$ x $58 \mathrm{~cm}$

(Sumber: Dokumentasi penulis)

Karya ini bercerita tentang kejadian bunuh diri yang dieksploitasi dan dijadikan pertunjukan oleh kebanyakan masyarakat. Banyak kejadian yang dianggap menarik oleh sebagian besar masyarakat. Misalnya kecelakaan lalu lintas, orang tenggelam di sungai atau pembunuhan. Apa lagi jika tragedi itu adalah bunuh diri, bisa dipastikan jika animo masyarakat yang menyaksikan sangatlah dahsyat. Saat menyaksikan kejadian fenomena serupa di kehidupan nyata, penulis bingung dan merasa ada keanehan, sekaligus bertanya dalam hati, sebenarnya mereka peduli atau hanya ingin menyaksikan kejadian itu saja.

Pada karya ini menggambarkan seorang gadis yang mati tergantung di seutas tali di sebuah pohon, di mana orang-orang di sekitarnya hanya menyaksikan saja. Ada wartawan yang malah memanfaatkan tragedi tersebut untuk tujuan tertentu. Ada yang malah berjualan selayaknya sedang ada acara pesta dan sejenisnya, ada juga ibu-ibu yang sedang menyuapi anaknya sambil menyaksikan kejadian tersebut, seolah mengajak anaknya ke tempat hiburan. Kenapa ibu dan anak, penulis mempunyai imajinasi bahwa salah satu pemandangan yang paling indah di dunia adalah ketika seorang ibu sedang menyuapi anaknya sembari mengajak anaknya jalan-jalan atau bercengkrama dengan tetangga. Kemudian terdapat seseorangyang sedang berjualan es dan pembelinya, yang melambangkan manusia Indonesia tidak peduli kejadian apapun mereka akan tetap melihat seolah seperti sedang menyaksikan drama di televisi.

\section{E. Kesimpulan}

Berdasarkan dari apa yang diuraikan, dari keresahan dan empati terhadap adanya paradoks yang terjadi di setiap tragedi yang menjadi inspirasi dalam pembuatan karya cetak seni grafis. Keresahan dan empati terhadap orangorang yang meraih keuntungan dari se- 
tiap peristiwa tragedi khususnya bunuh diri, muncul gagasan-gagasan yang ingin diungkapkan melalui media seni berbentuk seni cetak grafis dengan referensi seniman dan memperdalam topik permasalahan dalam proses perwujudan karya. Pembelajaran diri menyikapi berbagai masalah yang diresahkan seorang seniman. Lewat berbagai permasalahan seorang seniman dituntut kritis menyikapi setiap permasalahan yang mengganggu pikiran, lewat berkarya seorang seniman bisa menyampaikan apa yang dipikirkan. Ketika apa yang dipermasalahkan diungkap lewat sebuah karya, seorang seniman juga dituntut belajar mendalami apa yang dipermasalahkan dengan terus belajar dengan apa yang ingin diungkapkan agar tidak ada kerancuan. Karya seni sebagai media komunikasi visual untuk memahaminya diharuskan dilihat dan dirasakan tanpa adanya teks dalam memahaminya.

Proses pembuatan karya menggunakan teknik cukil kayu seni grafis dengan pewarnaan reduksi. Proses percetakan yang lama dan perbedaan pemilihan warna dalam setiap karya mempuntai tingkat kesulitan tersendiri. Beberapa karya menggunakan 10 warna dengan teknik goresan cukil kayu yang berbeda-beda. Tahap penyelesaian karya secara teknik harus matang dari pembuatan kento, pemilihan warna dan eksplore teknik cukilan dan konsep cerita yang ingin disampaikan. Proses yang begitu panjang dengan tingkat kesempurnaan yang ingin dicapai dalam setiap karya bertemakan paradoks bunuh diri ini membutuhkan ketelitian dan kesabaran tinggi. Beberapa karya ada yang di ciptakan hanya menggunakan satu warna, dengan pewarnaan yang sedikit proses pembuatannya tidak terlalu rumit hanya karakter cukilan dipertegas agar sesuai dengan karakter cukilan yang ingin dicapai. Keuntungan dengan pengambilan satu warna, goresan pisau cukil lebih terasa jelas karena fokus tidak terlalu terpecah dalam banyak warna.

Penciptaan karya teknik cukil kayu dengan pewarnaan reduksi ini, mengajarkan bagaimana pemikiran matang tidak terburu-buru akan menciptakan hasil karya yang memuaskan. Perasaan puas yang diawali dari sebuah proses panjang terbayar lunas dengan hasil yang sangat memuaskan dari hasil karya yang tercipta.

\section{Daftar Pustaka}

Al-Husain, S. (2005). Mengapa Harus Bunuh Diri. Jakarta: Qisthi Press. Prawira, N. G. (2016). Benang mer ah seni rupa modern. Satunusa.

Kartika, Dharsono Sony. (2004). Seni Rupa Modern. Bandung: Rekayasa sains.

Lubis, M. (2013). Manusia Indonesia. Yayasan Pustaka Obor Indonesia. Sacilotto, Donald Saff Deli (1978). Printmaking history and process. Australia.

Snijders, A. (2004). Antropologi filsafat ma nusia: paradoks dan seruan. Kanis ius.

Sugiyanto. (2002). Seni Rupa Barat (re alisme, pelukis-pelukis pemandan gan), Diktat kuliah pada Program Studi Seni Murni, Fakultas Seni Rupa, Institut Seni Indonesia Yogyakarta.

Suharso, \& Retnoningsih, A. (2009). Kamus besar Bahasa Indonesia. Widyakarya.

Tinarbuko, S. (2008). Semiotika komu nikasi visual: metode analisis tanda dan makna pada karya desain ko munikasi visual. Yogyakarta: Jala sutra. 